\title{
EFEITO DA DESODORIZAÇÃO NAS CARACTERÍSTICAS SENSORIAIS DE EXTRATOS HIDROSSOLÚVEIS DE SOJA OBTIDOS POR DIFERENTES PROCESSOS TECNOLÓGICOS ${ }^{1}$
}

\author{
Roberto Machado de MORAES ${ }^{2, *}$, Niurka M. A. HAJ-ISA ${ }^{3, *}$, \\ Tereza Cristina Avancini de ALMEIDA ${ }^{4}$, Roberto H. MORETTI ${ }^{5}$
}

\begin{abstract}
RESUMO
Os produtos derivados de soja apresentam múltiplas vantagens tecnológicas e nutricionais. Entretanto, eles são pouco aceitos pela população brasileira devido às características sensoriais indesejáveis, principalmente de odor e sabor. Uma alternativa para a remoção de compostos voláteis que conferem essas características é a desodorização. Extratos hidrossolúveis de soja, comumente conhecidos como leite de soja, foram obtidos por três processos diferentes e, posteriormente, desodorizados por vapor de água superaquecido à pressão atmosférica. Os produtos nas formas bruta e desodorizada foram avaliados sensorialmente por análise descritiva quantitativa. Os resultados mostraram eficiência da desodorização pela redução do odor de feijão cru e sabor residual, com aumento do sabor característico, nos processos de obtenção do leite por vaca mecânica e por maceração.

Palavras-chave: extrato hidrossolúvel de soja, leite de soja, desodorização, análise descritiva quantitativa.
\end{abstract}

\section{SUMMARY}

EFFECTS OF DEODORIZATION ON SENSORY CHARACTERISTICS OF HYDRO SOLUBLE SOYBEAN EXTRACTS OBTAINED FROM DIFFERENT TECHNOLOGICAL PROCESSES. The products obtained from the soybean have shown multiple technological and nutritious advantages but, in spite of that, they haven't been easily accepted by Brazilian consumers mainly because of their unpleasant sensory characteristics of odor and flavor. Deodorization can be a good and effective method in the attempt to remove the volatile compounds that produce these characteristics. Hydro soluble soybean extracts, commonly known as soybean milk, have been obtained from three different processes and, later on, submitted to deodorization process from steaming, at atmospheric pressure. The products, both in the natural and deodorized states, have been evaluated by Quantitative Descriptive Analysis. The results have shown that the deodorization process has been effective, reducing both the raw soybean odor and the aftertaste as well, improving the typical flavor in the processes of getting the milk from "mechanical cow" or maceration.

Keywords: hydro soluble soybean extracts, soybean milk, deodorization, quantitative descriptive analysis.

\section{1 - INTRODUÇÃO}

A soja chegou ao Brasil em fins do século XIX e a expansão de sua cultura foi beneficiada pelos trabalhos de adaptação, produtividade e resistência a pragas realizados por diferentes universidades e centros de pesquisas, como o Instituto Agronômico de Campinas (IAC), a Empresa Brasileira de Pesquisas Agropecuárias (Embrapa), entre outros, e pela utilização do excedente proveniente da alimentação animal na extração de óleo para fins comestíveis, pelos estudos realizados no Instituto de Tecnologia de Alimentos (Ital) e por uma longa lista de estudos nutricionais, que têm catalogado esta leguminosa como um alimento de alto valor biológico, funcional e nutracêutico [10, 11, 15].

A adição de proteínas de soja aos alimentos industrializados apresenta diversas vantagens tecnológicas, como o aumento de retenção de umidade, melhoria da textura, ligamento, coesão e rendimento final, retenção dos atributos de qualidade em geral, maior teor protéico, cor agradável,

\footnotetext{
${ }^{1}$ Recebido para publicação em 11/8/2004. Aceito para publicação em 23/1/2006 (001390)

${ }^{2}$ Tecnologia de Alimentos (Ital). Campinas (SP).E-mail: roma@ital.sp.org.br ${ }^{3}$ Fundação Municipal de Ensino Superior de Bragança Paulista (Fesb). São Paulo.E-mail:niurka_hajisa@hotmail.com

${ }^{4}$ Prefeitura de Campinas (SP).E-mail:tereza_almeida@uol.com.br

${ }^{5}$ Universidade Estadual de Campinas DTA/FEA/Unicamp. Campinas (SP).

E-mail:moretti@fea.unicamp.br

*A quem a correspondência deve ser enviada
}

maior vida de prateleira, melhor palatabilidade, melhor aparência e valor nutricional [2].

A inclusão da soja e seus derivados como parte da dieta diária é altamente recomendável, pois contribuem para prover os nutrientes necessários para o desenvolvimento, crescimento e manutenção do organismo, além de fornecer componentes, tais como antioxidantes naturais, isoflavonas e fosfolipídios, entre outros, que auxiliam no bem-estar físico, melhorando o funcionamento do organismo e prevenindo doenças crônico-degenerativas [5, 12].

O extrato hidrossolúvel de soja (EHS), conhecido popularmente como leite de soja, é um dos derivados, não fermentados, obtido a partir do grão da leguminosa, sendo de fácil obtenção, mesmo domesticamente. Esse produto é amplamente difundido na alimentação nos países orientais, mas na nossa cultura há uma barreira para seu uso, devido ao sabor desagradável oriundo de compostos existentes no interior dos grãos e de outros formados durante o processo de obtenção [10].

O sabor típico de soja crua ou de erva tem limitado a inclusão do EHS no hábito alimentar do brasileiro. Ele aparece por ação das enzimas lipoxidase e lipoxigenase quando os grãos de soja são rompidos [14]. Os gostos amargos têm como precursores os aminoácidos liberados da proteólise e por deterioração oxidativa [6, 7].

Os compostos responsáveis pelos sabores desagradáveis estão presentes no grão de soja ou são formados durante o processo de obtenção do leite, quer pela ação do calor, quer 
pela ação de enzimas presentes no grão, principalmente a lipoxigenase [14]. Esses autores realizaram a separação de aproximadamente 80 compostos voláteis, tendo sido identificados mais de 40. Entre os principais compostos estão: aldeídos, acetais, ésteres, compostos sulfurados, hidrocarbonetos, cetonas, álcool 1-pentilfurano, ácido hexanóico, gama-nanolactona e o hexanal, este último, o componente volátil que se forma em maior quantidade. A maioria desses compostos tem odor desagradável, especialmente a etilvinilcetona, que apresenta sabor típico de soja crua [14, 17].

As isoflavonas da soja apresentam-se na forma glicosídica e de agliconas, sendo a genistina e a daidzina os principais compostos encontrados. Esses compostos têm sido responsabilizados pelos sabores adstringente e amargo dos produtos derivados da soja [7], os quais persistem após inativação da lipoxigenase [1,4]. De modo geral, aquecimento úmido ou por vapor direto, utilizados isoladamente em grãos de soja, são eficientes na inativação da lipoxigenase [14]. Concentrados protéicos de soja processados para reter altos níveis de isoflavonas conseguem proporcionar paladar "macio" e sabor neutro aos produtos nos quais são adicionados [8].

MORAES (2002) desenvolveu um equipamento desodorizador por vapor de água superaquecido, à pressão atmosférica, em coluna recheada com anéis de vidro, que permitiu o arraste de diversos compostos formados durante o processamento do EHS [13]. Para o preparo do EHS, foram empregadas três técnicas diferentes; posteriormente os leites obtidos foram desodorizados: (1) "vaca mecânica”, que consistiu na maceração de grãos de soja descascados durante $2 \mathrm{~h}$ em água fria. A seguir, os grãos foram separados da água de maceração e colocados em água fervente por 2 min e triturados na mesma água, sendo o produto resultante, centrifugado, e o leite, separado do seu resíduo sólido por uma peneira; (2) maceração, na qual os grãos de soja com casca foram macerados com água na proporção de 1:2 durante $12 \mathrm{~h}$ à temperatura de $25^{\circ} \mathrm{C}$ e imediatamente triturados com água em ebulição durante $3 \mathrm{~min}$ à temperatura de $90-95^{\circ} \mathrm{C}$. Em seguida, a mistura foi separada utilizando-se um pano de dessora; e (3) sem maceração, que se diferencia do processo anterior apenas por não macerar os grãos. Antes da desodorização, foram adicionados às amostras seis padrões de compostos responsáveis pelas características sensoriais desagradáveis existentes no EHS, sendo um aldeído, o hexanal; três álcoois, o 1-hexanol, o 1-octeno-3-ol e o 1-octanol; um composto heterocíclico, o 2-amilfurano; e uma cetona a 3-octeno-2-ona. A porcentagem de remoção desses padrões foi avaliada por meio da Cromatografia em fase gasosa [10].

Com o processo de desodorização utilizado, o autor mostrou ser possível a remoção dos compostos de off-flavors adicionados, portanto, também a remoção daqueles compostos formados no leite durante o processamento. A eficiência da desodorização foi maior para as amostras em que os grãos eram macerados em água [10].

O presente trabalho teve como objetivo avaliar, sensorialmente, a eficiência do processo de desodorização desenvolvido por MORAES [10], na retirada de compostos responsáveis pelas características sensoriais desagradáveis do EHS. Amostras de extratos hidrossolúveis de soja desodorizadas e os correspondentes extratos brutos, obtidos pelos três processos descritos anteriormente, foram avaliados pelo método de análise descritiva quantitativa.

\section{2 - MATERIAL E MÉTODOS}

\section{1 - Material}

Grãos de soja da variedade BR-16 foram empregados na obtenção de EHS por três processos diferentes: "vaca mecânica”, maceração e sem maceração. Os leites obtidos foram, posteriormente, desodorizados por vapor de água superaquecido, à pressão atmosférica, em coluna recheada com anéis de vidro. Em cada batelada, aproximadamente 5 L de EHS foram obtidos [10].

Os leites foram avaliados sensorialmente na sua forma desodorizada e não-desodorizadas, compondo seis amostras, identificadas como:

- $\quad$ LMB - leite de soja obtido pelo processo "vaca mecânica";

- $\quad$ LMD - leite de soja obtido pelo processo "vaca mecânica" e desodorizado;

- LEB - leite de soja obtido pelo processo de maceração;

- LED - leite de soja obtido pelo processo de maceração e desodorizado;

- $\quad$ LVB - leite de soja obtido pelo processo sem maceração;

- $\quad$ LVD - leite de soja obtido pelo processo sem maceração e desodorizado.

Os produtos obtidos foram congelados para sua melhor preservação até o momento de avaliação. Antes de cada sessão um volume suficiente de cada leite foi descongelado e homogeneizado.

\section{2 - Método}

\subsection{1 - Preparo das amostras}

Foram servidos cerca de $30 \mathrm{~mL}$ de EHS puro, a $25 \pm 1^{\circ} \mathrm{C}$, apresentados aos provadores em copos plásticos brancos descartáveis, de $50 \mathrm{~mL}$, com numeração aleatória de três dígitos, conjuntamente com água à temperatura ambiente e bolachas água e sal, para eliminar qualquer sabor residual que interferisse na avaliação entre as amostras.

Para eliminar a interferência de odor de uma amostra sobre a outra, foi solicitado aos provadores que antes de avaliar o odor de cada amostra cheirasse grãos de café, colocados em frasco plástico com tampa. Por consenso entre os provadores, na avaliação dos atributos de odor, as amostras foram acondicionadas em frascos de vidro com tampa esmerilada, contendo $75 \mathrm{~mL}$. 


\subsection{2 - Análise descritiva quantitativa}

O método empregado para a avaliação sensorial dos produtos em estudo foi uma adaptação da análise descritiva quantitativa [16], visando identificar, descrever e medir a intensidade das principais sensações de sabor e odor percebidas nas amostras.

\subsubsection{1 - Pré-seleção da equipe}

Inicialmente foi feito um recrutamento de candidatos a provadores, com base em interesse, disponibilidade de tempo e aspectos de saúde. Após orientação sobre a análise a ser realizada, procedeu-se à pré-seleção dos candidatos com base nas habilidades discriminativas. Foi aplicado o teste triangular com repetições em sessões diferentes, totalizando quatro testes, utilizando-se amostras LEB e LED. Como critério de seleção foi escolhido um mínimo de $75 \%$ de acertos.

\subsubsection{2 - Levantamento de atributos}

Para o desenvolvimento da terminologia descritiva foi aplicado o Método de Rede [11]. Embora o enfoque deste trabalho fossem os atributos odor e sabor, foi solicitado aos provadores que descrevessem similaridades e diferenças também para aparência e textura. Foram apresentados três pares de amostras (LMB vs. LMD, LEB vs. LED, LVB vs. LVD).

\subsubsection{3 - Treinamento e seleção final da equipe sensorial}

Após o desenvolvimento da lista de termos descritivos levantados pelo painel chegou-se, por consenso, em duas sessões abertas com todos os provadores, a uma lista de seis atributos, sendo definidas e desenvolvidas amostras de referências para cada um deles nos seus respectivos extremos de intensidade mínima e máxima na escala.

Os provadores foram treinados quanto ao uso de escala não estruturada de $9 \mathrm{~cm}$, ancorada nos extremos com os termos de mínima intensidade na extremidade esquerda e os de máxima intensidade na extremidade direita.

Com base no poder discriminativo dos provadores $(\mathrm{p} \leq 0,05)$ e na reprodutibilidade dos resultados apresentados por eles ( $\mathrm{p} \geq 0,30$ ), a equipe selecionada foi treinada para avaliação de EHS.

\subsubsection{4 - Avaliação das amostras de leite de soja}

A avaliação das amostras foi feita com base nas definições dos termos e das referências dos extremos de escalas estabelecidas durante o treinamento, utilizando escalas não estruturadas de $9 \mathrm{~cm}$.

Todas as sessões de análise sensorial foram realizadas em cabines individuais, sob temperatura controlada $\left(25 \pm 1^{\circ} \mathrm{C}\right)$ e luz branca.

As amostras de EHS foram avaliadas utilizando-se delineamento experimental de blocos completos balanceados, de forma monádica em três repetições. A ordem de apresentação das amostras foi balanceada entre os provadores seguindo delineamento para seis amostras [9].

\subsubsection{5 - Análise dos dados}

Com o auxilio do programa Excel, da Microsoft [3], os resultados da seleção final e avaliação de amostras foram analisados por análise de variância (ANOVA) fator duplo (provador e tratamento) com repetição, sendo determinada a significância estatística das diferenças entre as médias por meio do teste de Tukey, para o nível de significância $\mathrm{p} \leq 0,05$. Para facilitar a visualização dos efeitos da desodorização, foi construído um gráfico tipo "aranha” para cada processo.

\section{3 - RESULTADOS E DISCUSSÃO}

\section{1 - Pré-seleção e treinamento de provadores}

A equipe selecionada, constituída por 11 mulheres, na faixa etária de 17-21 anos, escolheu, em consenso, os termos a serem utilizados na avaliação do produto: cor bege, odor característico de EHS, odor de feijão cru, sabor característico de EHS, sabor residual e adstringência. A Tabela 1 apresenta a descrição de cada atributo avaliado, assim como, as referências de mínimo e máximo da escala para cada atributo.

\section{2 - Avaliação das amostras de leite de soja}

Pela Tabela 2 observa-se que no atributo cor bege houve diferença significativa $(\mathrm{p} \leq 0,05)$ entre as amostras desodorizadas e sua similar bruta, havendo um aumento na intensidade da cor bege dos leites quando desodorizados. A desodorização do leite obtido pelo processo "vaca mecânica" foi o que provocou maior escurecimento do leite.

No atributo "odor de feijão cru" houve diferença significativa $(\mathrm{p} \leq 0,05)$ entre as amostras desodorizadas e sua similar bruta sendo a intensidade do odor menor quando o leite foi desodorizado (Tabela 2). Já a intensidade do odor característico foi significativamente maior $(\mathrm{p} \leq 0,05)$ nos leites de soja desodorizados, com exceção dos leites extraídos sem prévia maceração dos grãos, nos quais não foi percebida diferença significativa entre os leites bruto e desodorizado (LVB, LVD).

Destaca-se, também, que em relação ao sabor característico de leite de soja as amostras de leite desodorizadas diferiram, significativamente $(p \leq 0,05)$, das brutas, independentemente do processo de obtenção do leite. A intensidade do sabor característico de EHS foi maior nos leites desodorizados LMD e LED. No LVD não houve diferença neste atributo em relação ao leite bruto. Inversamente, o sabor residual foi significativamente $(\mathrm{p} \leq 0,05)$ maior nas amostras brutas em relação às suas similares desodorizadas.

O EHS obtido sem maceração dos grãos (LVB) foi o que apresentou menores intensidades de odor de feijão cru e 
TABELA 1 - Atributos, descrição e referências para extremos de escala utilizados na avaliação de leite de soja

\begin{tabular}{|c|c|c|}
\hline Atributos & Descrição & Extremos \\
\hline \multirow[t]{2}{*}{ Cor bege } & \multirow[t]{2}{*}{ Intensidade da cor bege } & claro: Cor do leite de soja obtido por maceração (LEB) \\
\hline & & escuro: Cor do leite de soja obtido em vaca mecânica e desodorizado (LMD) \\
\hline \multirow{2}{*}{$\begin{array}{l}\text { Odor característico } \\
\text { de leite de soja }\end{array}$} & \multirow{2}{*}{$\begin{array}{l}\text { Conjunto de aromas presentes no leite de soja e } \\
\text { que o caracterizam }\end{array}$} & fraco: Odor do leite de soja obtido sem maceração e desodorizado (LVD) \\
\hline & & forte: Odor do leite de soja obtido em vaca mecânica (LMB) \\
\hline \multirow[t]{2}{*}{ Odor feijão cru } & \multirow{2}{*}{$\begin{array}{l}\text { Conjunto de aromas presentes no líquido obtido } \\
\text { na segunda desodorização do leite de soja obtido } \\
\text { por maceração e desodorizado (LED) }\end{array}$} & fraco: Diluição em água do condensado obtido na desodorização do LED (1:6) \\
\hline & & forte: Diluição em água do condensado obtido na desodorização do LED (1:3) \\
\hline \multirow{2}{*}{$\begin{array}{l}\text { Sabor característico } \\
\text { de leite de soja }\end{array}$} & \multirow[t]{2}{*}{ Sabor próprio que caracteriza o produto } & fraco: Sabor do leite de soja obtido sem maceração (LVB) \\
\hline & & forte: Sabor do leite de soja obtido em vaca mecânica (LMB) \\
\hline \multirow[t]{2}{*}{ Sabor residual } & \multirow[t]{2}{*}{$\begin{array}{l}\text { Sabor de leite de soja, salgado e oleoso, que } \\
\text { permanece na boca após ter engolido a amostra }\end{array}$} & $\begin{array}{l}\text { fraco: Solução aquosa }(5: 100 \mathrm{~mL}) \text { da mistura de padrões (hexanal, 1-hexanol, } \\
\text { 1-octeno-3ol, 1-octanol, 2-amilfurano, 3-octeno-2-ona) }\end{array}$ \\
\hline & & $\begin{array}{l}\text { forte: Solução aquosa (15:100 mL) da mistura de padrões (hexanal, 1-hexanol, } \\
\text { 1-octeno-3ol, 1-octanol, 2-amilfurano, 3-octeno-2-ona) }\end{array}$ \\
\hline \multirow[t]{2}{*}{ Adstringência } & \multirow[t]{2}{*}{$\begin{array}{l}\text { Sensação de "seco" percebida na boca causada } \\
\text { pela contração da superfície da mucosa oral }\end{array}$} & $\begin{array}{l}\text { fraca: Solução aquosa }(5: 100 \mathrm{~mL}) \text { do condensado obtido na segunda desodorização } \\
\text { do LEB }\end{array}$ \\
\hline & & $\begin{array}{l}\text { forte: Solução aquosa ( } 15: 100 \mathrm{~mL}) \text { do condensado obtido na segunda desodorização } \\
\text { do LEB }\end{array}$ \\
\hline
\end{tabular}
macerac̃ão. LED - leite de soja obtido pelo processo de maceração e desodorizado. LVB - leite de soja obtido pelo processo sem maceração. LVD - leite de soja obtido pelo proc sem maceração e desodorizado

sabor residual tanto antes quanto depois do processo de desodorização (LVD).

Não houve diferenças, estatisticamente significativas $(\mathrm{p} \leq 0,05)$, entre as amostras brutas e suas similares desodorizadas para o atributo adstringência. Porém, observou-se que a intensidade da adstringência das amostras obtidas em "vaca mecânica" (LMB, LMD) foi significativamente maior que das amostras obtidas sem maceração dos grãos (LVB, LVD), sugerindo que esse atributo sensorial é influenciado pelo processo de obtenção do leite.

A Figura 1 apresenta a configuração da análise descritiva quantitativa das amostras para os atributos avaliados. $\mathrm{O}$ centro da figura representa o extremo de menor intensidade da escala utilizada na ficha de avaliação. A intensidade de cada atributo (representado pelos eixos), para cada amostra, é maior quanto maior for sua distância do centro do gráfico. A união dos pontos referentes à média obtida em cada atributo forma a figura representativa do perfil sensorial de cada amostra. Para facilitar a visualização do efeito da desodorização, foram construídos três gráficos correspondentes a cada processo estudado neste trabalho, comparando-se as amostras desodorizadas e não-desodorizadas, uma vez que o objetivo central é verificar o efeito da desodorização.

Avaliando-se de forma comparativa o perfil sensorial das amostras de leites de soja, a Figura 1 sugere que de uma forma geral a desodorização modificou as características sensoriais dos leites de soja obtidos pelos três processos; as maiores diferenças entre as médias, por atributo, estão em cor bege e sabor característico de soja. As amostras LMD e LED apresentaram maior intensidade de odor e sabor característicos de EHS, assim como da cor bege (Tabela 2).

O sistema de desodorização do leite obtido da soja permite obter EHS desodorizados que poderiam ser aromatizados com sabores de frutas ácidas, caramelo, chocolate, coco e nozes, possibilitando atender às preferências dos consumidores [10].

TABELA 2 - Notas médias* por atributos avaliados em leite de soja

\begin{tabular}{|c|c|c|c|c|c|c|}
\hline \multirow{2}{*}{ Atributos } & \multicolumn{6}{|c|}{ Amostras de leite de soja } \\
\hline & LMB & LMD & LEB & LED & LVB & LVD \\
\hline Cor bege & $2,89^{c}$ & $7,40^{\mathrm{a}}$ & $2,69^{c}$ & $4,48^{b}$ & $2,57^{c}$ & $3,47^{\mathrm{bc}}$ \\
\hline Odor de feijão cru & $2,51^{\mathrm{ab}}$ & $1,66^{c}$ & $3,07^{a}$ & $1,60^{c}$ & $1,91^{b}$ & $0,61^{\mathrm{d}}$ \\
\hline Odor característico de leite de soja & $4,24^{\mathrm{bc}}$ & $6,20^{\mathrm{a}}$ & $3,89^{c}$ & $5,49^{a}$ & $5,03^{b}$ & $4,13^{\mathrm{bc}}$ \\
\hline Sabor característico de leite de soja & $3,31^{c}$ & $6,19^{a}$ & $3,12^{d}$ & $5,45^{\mathrm{a}}$ & $3,23^{\text {cd }}$ & $4,29^{b}$ \\
\hline Sabor residual & $3,75^{\mathrm{a}}$ & $3,07^{\mathrm{bc}}$ & $3,54^{\mathrm{ab}}$ & $2,63^{c}$ & $2,81^{c}$ & $1,90^{\mathrm{d}}$ \\
\hline Adstringência & $3,19^{a}$ & $3,07^{a}$ & $2,86^{a b}$ & $2,54^{\mathrm{ab}}$ & $2,40^{\mathrm{b}}$ & $2,14^{b}$ \\
\hline
\end{tabular}

*Médias com letras iguais na mesma linha, não diferem estatisticamente entre si pelo teste de Tukey (p $\leq 0,05$ ). LMB - leite de soja obtido pelo processo "vaca mecânica". LMD - leite de soja obtido pelo processo "vaca mecânica" e desodorizado. LEB - leite de soja obtido pelo processo de maceração. LED - leite de soja obtido pelo processo de maceração e desodorizado. LVB - leite de soja obtido pelo processo sem maceração. LVD - leite de soja obtido pelo processo sem maceração e desodorizado 


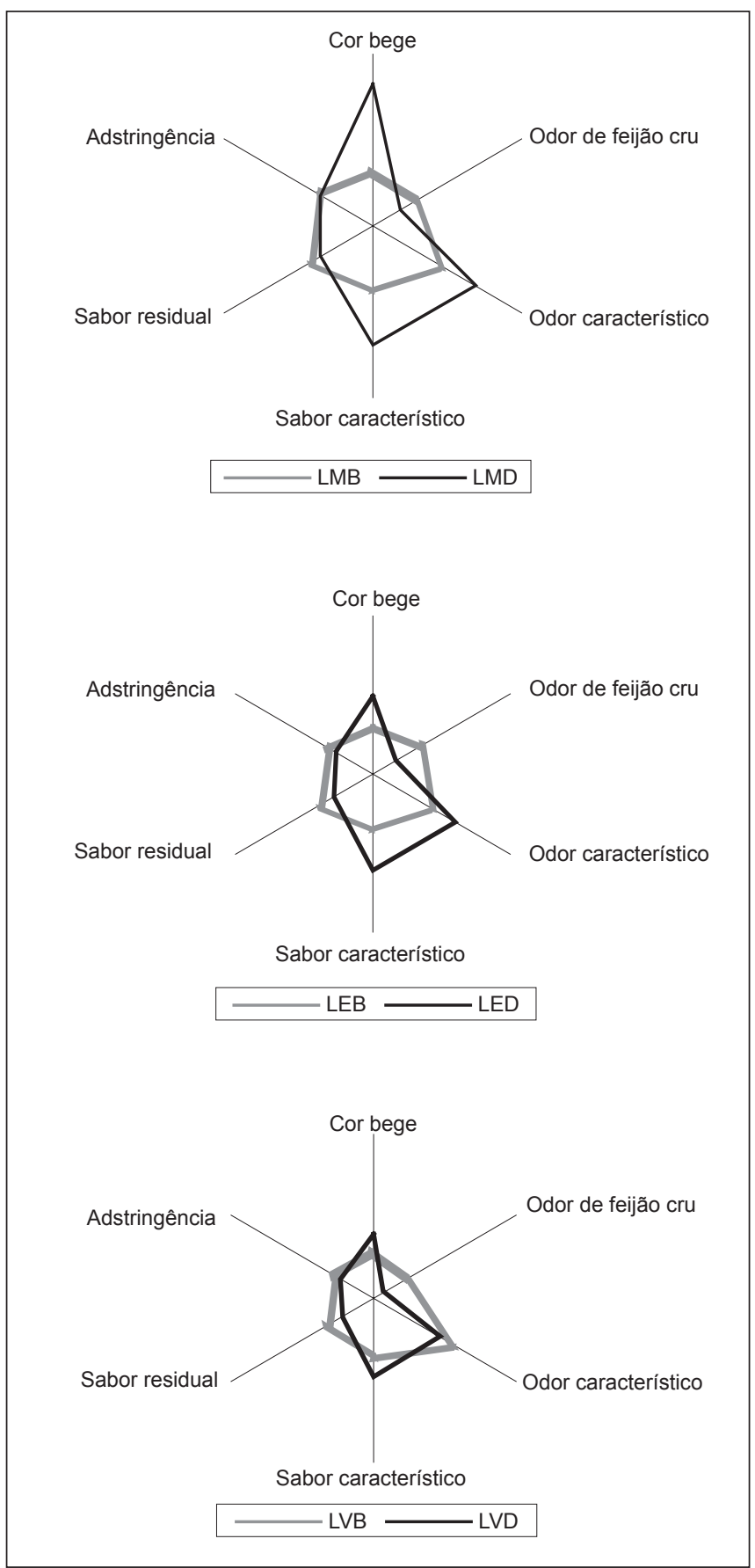

FIGURA 1 - Perfil sensorial das amostras de leite de soja LMB - leite de soja obtido pelo processo "vaca mecânica". LMD - leite de soja obtido pelo processo "vaca mecânica" e desodorizado. LEB - leite de soja obtido pelo processo de maceração. LED - leite de soja obtido pelo processo de maceração e desodorizado. LVB - leite de soja obtido pelo processo sem maceração. LVD - leite de soja obtido pelo processo sem maceração e desodorizado

\section{4 - CONCLUSÕES}

O processo de desodorização, de uma forma geral, melhorou as características sensoriais dos leites de soja. Os melhores resultados foram obtidos quando extraído o leite em vaca mecânica (LMB) e maceração (LEB), amostras essas que apresentaram menor odor de feijão cru, maior sabor e odor característico de EHS e menor sabor residual.
O processo de obtenção de leite sem maceração dos grãos foi o menos beneficiado sensorialmente pela desodorização, pois não alterou significativamente a intensidade do odor característico de EHS, e foi a amostra com menor sabor característico de soja.

Houve diferenças entre as amostras desodorizadas e sua similar bruta em quase todos os atributos, com exceção da adstringência.

\section{5 - REFERÊNCIAS BIBLIOGRÁFICAS}

[1] ALMEIDA, L.A. de; KIIHL, R.A. de S.; PÍPOLO, A.E.; GOMIDE, F.B.; MIRANDA, L.C.; ARIAS, C.A.A.; KASTER, M.; YORINORI, J.T.; DOMIT, L.A.; VIEIRA, O. V.; SILVA, J.F.V.; DIAS, W.P.; TOLEDO, J.F.F. de; CARNEIRO, G.E. de S.; ALMEIDA, A.M.R. BRS 230: nova cultivar de soja para Região Centro-Sul. In: Reunião de Pesquisa de Soja da Região Central do Brasil, 25, 2003, Uberaba. Resumos... Londrina, Embrapa Soja, Epamig, Fundação Triângulo, 2003. p. 81-82. (Embrapa Soja, Documentos, 209).

[2] ARAÚJO, J.M.A.; CARLOS, J.C.S.; SEDYAMA, C.S. Isoflavonas em grãos de soja: importância da atividade de $\beta$-glicosidase na formação do sabor amargo e adstringente. Ciência e Tecnologia de Alimentos. Campinas, v. 17, n. 2, p. 137-141, 1997.

[3] FERREIRA, V.L.P.; ALMEIDA, T.C.A.; PETTINELLI, M.L.C.V.; SILVA, M.A.A.P.; CHAVES, J.B.P. \& BARBOSA, E.M.M. Análise sensorial: testes discriminativos e afetivos. Manual: série de qualidade. Campinas, SP, CBCTA, 127 p. 2000.

[4] FERREIRA, C.V.; MORAES, R.M. Desodorização de leite de soja - resumo. Congresso Brasileiro de Soja. Londrina, Paraná, Brasil, 17-20 mai. de 1999.

[5] FERREIRA, V.L.P.; SANTOS, L.C.; DO VALLE, J.L.E. Estabilidade e aceitabilidade do leite de soja formulado. Boletim do Ital. Campinas, v. 23, n. 4, p. 425-436, 1986.

[6] GOOSSENS, A.E. Protein foods; flavors and off-flavors. Food Engineering. New York, v. 46, n. 10, p. 59-60, Oct. 1974.

[7] KITAMURA, K. Breeding trials for improving the foodprocessing quality of soybeans. Trends in food science and technology. London, v. 4, p. 64-67, 1995.

[8] KUHN, M. Functional foods overdose. Food processing. Chicago, v. 59, n. 5, p. 21-48, 1998.

[9] LAMEGO, F.P., FLECK, N.G., BIANCHI, M.A. et al. Tolerância à interferência de plantas competidoras e habilidade de supressão por genótipos de soja: II. Resposta de variáveis de produtividade. Planta daninha, out.-dez. 2004, v. 22, n. 4, p. 491-498, ISSN 0100-8358.

[10] MACFIE, H.J.; BRATCHELL, N.; GREENHOFF, K.; VALLIS, L. Designs to balance the effect of order of presentation and first-order-carry-over effects in hall tests. Journal of Sensory Studies, n. 4, p. 129-148, 1989.

[11] MIURA, Edna Mayumi Yuahasi; BINOTTI, Marco Aurélio R.; CAMARGO, Daliane Souza de et al. Avaliação biológica de linhagem de soja com baixa atividade de inibidores de tripsina. Rev. Bras. Zootec., nov.-dez. 2000, v. 29, n. 6, p. 1.754-1.758, ISSN 1516-3598. 
[12] MONTEIRO, M.R.P.; COSTA, N.M.B.; OLIVEIRA, M.G.A. et al. Qualidade protéica de linhagens de soja com ausência do Inibidor de Tripsina Kunitz e das isoenzimas Lipoxigenases. Rev. Nutr., abr.-jun. 2004, v. 17, n. 2, p. 195-205.

[13] MORAES, R.M. de. Montagem e avaliação de um equipamento para desodorização de leite de soja por arrastre de vapor superaquecido. Campinas. Tese de doutorado em Tecnologia de Alimentos. Faculdade de Engenharia de Alimentos. Universidade Estadual de Campinas (Unicamp). 2002.

[14] MOSKOWITTZ, H.R. Product testing and sensory evaluation of foods-marketing and R \& D approsches.
Food \& Nutrition Press, Inc. Westport, 605 p., 1983.

[15] SOUZA, G.; VALLE, J.L.E.; MORENO I. Efeitos dos componentes da soja e seus derivados na alimentação humana. Bol. SBCTA. Campinas, v. 34, n. 2, p. 61-69, 2000.

[16] STONE, H.; SIDEL, J.; OLIVER, S.; WOOLSEY, A.; SINGLETON, R.C. Sensory evaluation by quantitative descriptive analysis. Food Technology, v. 28, n. 11, p. 24-34, 1974.

[17] WILKENS, W.F; LINS, F.M. Gas chromatographic and mass spectral analyses of soybean milk volatiles. Journal of Agricultural and Food Chemistry. Washington, v. 18 , n. 3 , p. 333-335, 1970. 